Supporting Information

\title{
Overcoming hypoxia-restrained radiotherapy using an erythrocyte-inspired and glucose-activatable platform
}

Hao Huang, ${ }^{\ddagger, \#}$ Chao Zhang, ${ }^{\ddagger, \#}$ Xiaolin Wang, ${ }^{\$, \# ~ J i n s o n g ~ S h a o, ~}{ }^{\ddagger}$, Chao Chen, ${ }^{\ddagger}$ Haoming

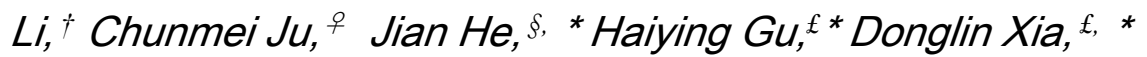

£ School of Public Health, Nantong University, Nantong, Jiangsu 226019, P.R. China

$\$$ Institute of Materials Engineering, College of Engineering and Applied Sciences, Nanjing

University, Nanjing, Jiangsu, 210093, P. R. China

$\dagger$ Medical school of Nantong University, Nantong, Jiangsu 226019, P.R. China

\$ Nantong Tumor Hospital, Nantong, Jiangsu 226362, P.R. China

$\S$ Department of Radiology, Nanjing Drum Tower Hospital, The Affiliated Hospital of

Nanjing University Medical School, Nanjing University, Jiangsu, 210008, P. R. China.

${ }^{9}$ Affiliated Hospital of Nantong University, Nantong, Jiangsu 226001, P.R. China

*Corresponding author. E-mail: hjxueren@126.com (J. He); hygu@ntu.edu.cn (H.Y.

Gu); xiadonglin@ntu.edu.cn (D.L. Xia) 
\# Hao Huang, Chao Zhang and Xiaolin Wang contributed equally to this work.

KEYWORDS: Radiotherapy, Hypoxia, Angiogenesis, Erythrocytes, GOx 


\section{MATERIALS AND METHODS}

\section{Materials}

Endostar (Endo) was supplied by Shandong Xiansheng Pharmaceutical Co., Ltd (Shandong, China). Glucose oxidase (GOx) was purchased from Aladdin Biochemical Technology Co., LTD (Shanghai, China). Biotin and Dialysis bags (molecular-weight cutoff, $5 \mathrm{kDa}$ ) were purchased from Bomei Biotechnology (Hefei, China). All other reagents were analytical grade and used without further purification/modification.

Male Sprague-Dawley (SD) rats weighing 180-220 g, as well as BALB/c mice weighing 14-18 g, were obtained from the Experimental Animal Center of Nantong University. All animals were housed in a regulated environment $\left(22 \pm 1^{\circ} \mathrm{C}\right)$ with a $12 \mathrm{~h}$ light-dark cycle. Rats and mice were provided ad libitum access to food and water.

\section{Preparation of Endo@GOx-ER}

Fresh blood was obtained from SD rats and centrifuged at $750 \times \mathrm{g}$ for $10 \mathrm{~min}$. The concentration of Endo was 5.0 mg/mL. Endo-loaded erythrocytes (Endo@ER) were prepared using a hypotonic dialysis method. Concretely, a $1 \times 10^{13} / \mathrm{mL}$ cell suspension was prepared and mixed with Endo solution of different concentrations of at 1:1 (v/v) hematocrit. The cell suspension was incubated in a hypotonic buffer for a predetermined time at $4{ }^{\circ} \mathrm{C}$, in resealing buffer for $30 \mathrm{~min}$ at $37^{\circ} \mathrm{C}$, and then in PBS. The hypotonic buffer and resealing buffer were prepared as described previously. ${ }^{1}$ Different initial Endo concentrations $(2.5,5.0,7.5,10.0 \mathrm{mg} / \mathrm{mL})$ and dialysis time $(4,8,12,16$, 20, and $24 \mathrm{~h}$ ) were tested, as they are key contributing factors to optimal encapsulation.

The encapsulation efficiency and drug loading efficiency of Endo in erythrocytes were 
calculated as following:

Encapsulation efficiency $(\%)=$ Weight of loaded drug/ Total weight of Endo@GOx-ER X100\%

Drug loading efficiency (\%) = Weight of loaded Endo/Weight of feeding Endo $\times 100 \%$

Endo@GOx-ER was synthesized as follow: Birefly, biotin was immersed in GOx solution for 60 min with the presence of N,N'-carbonyldiimidazole at room temperature. ${ }^{2}$ To optimize the proportion between biotin-GOx and erythrocyte, different amount of biotin-GOx was transferred into Endo@ER solution for $12 \mathrm{~h}$ at $4{ }^{\circ} \mathrm{C}$. Eventually, Endo@ER-GOx were obtained by centrifugation and washed thrice by PBS to remove un-conjugated GOx. The GOx concentration was detected by glucose oxidase test kits (Best Bio, Shanghai, China).

\section{Characterisation of Endo@GOx-ER}

Morphological changes were assessed by scanning electron microscopy (SEM) using a JSM6700F microscope (JEOL, Japan). The Malvern Zeta Sizer (Malvern Instruments Ltd., UK) was used to determine zeta potential change of Endo@GOx-ER.

Additionally, hemoglobin (HGB), hematocrit (HCT), mean red blood cell volume (MCV), mean red blood cell hemoglobin $(\mathrm{MCH})$, and mean red blood cell hemoglobin concentration (MCHC), using the HEMAVET® 950FS Hematology System (Drew Scientific, Waterbury, CT, USA).

The GOx concentration was determined using the glucose oxidase method. Endo was stained with FITC, while GOx was stained with rhodamine B (red) during the development of Endo@GOx-ER. Fluorescence images were collected using a fluorescence microscope (Leica, Germany).

\section{In vitro release behavior of Endo@GOx-ER}


Based on the results shown in Figure 1C, increasing the Endo loading content leads to decreased Endo loading efficiency. For the in vivo tests followed, $5.0 \mathrm{mg} / \mathrm{mL}$ of initial Endo concentration, and $12 \mathrm{~h}$ dialysis time were chosen as optimal for the preparation of Endo@GOx-ER.

In vitro "close-loop" release behavior of Endo was tested as follow: 1 mL of Endo@GOx-ER was transferred into a dialysis bag (molecular-weight cutoff: $5 \mathrm{kDa}$ ) and was alternately immersed into $10 \mathrm{~mL}$ of normoglycemia (5 mM D-glucose) and Hyperglycemia (25 mM D-glucose) every $10 \mathrm{~min}$ at $37^{\circ} \mathrm{C}$. The concentration and release rate of Endo in the medium were determined separately by HPLC.

The release behavior of Endo in normoxia or hypoxia was studied as follow: $1 \mathrm{~mL}$ of Endo@GOx-ER was transferred into closed tubes and full with air (normoxia) or nitrogen (hypoxia). The glucose was added to release the Endo from Endo@GOx-ER. The concentration of Endo in the medium were determined separately by HPLC.

1mL of Endo@GOx-ER, prepared at different initial GOx concentrations (Group 1: initial GOx $0.1 \mathrm{mg} / 10^{10}$ cells, Group 2: initial GOx $0.5 \mathrm{mg} / 10^{10}$ cells, Group 3: initial GOx $1 \mathrm{mg} / 10^{10}$ cells, Group 4 : initial GOx $2 \mathrm{mg} / 10^{10}$ cells, Group 5 : initial GOx $4 \mathrm{mg} / 10^{10}$ cells), were administrated to mice by tail-vein injection. At indicated time-points, the supernatant was collected, and the Endo concentration was determined by HPLC.

The Endo@GOx-ER stability was tested as follows: After suspended in PBS for ten days at $4{ }^{\circ} \mathrm{C}$, Endo@GOx-ERs were immersed in a hyperglycemic solution $(25 \mathrm{mM})$ at $37^{\circ} \mathrm{C}$. The Endo concentration was determined by HPLC.

\section{Releasing mechanism of Endo@GOx-ER}




\section{a) Determination of membrane blocking degree}

For membrane blocking degree measurements, 0.6 mL of Endo@GOx-ER was transferred into a $1 \mathrm{~cm}$ path-length cuvette at $25{ }^{\circ} \mathrm{C}$. PBS (pH 8.4), $0.1 \%$ saponin (S), and $0.1 \mathrm{~mL}$ of $5 \mathrm{mM}$ $\mathrm{KFe}(\mathrm{CN})_{6}$ were added sequentially. ${ }^{3}$ Ten min later, $0.1 \mathrm{~mL} 6 \mathrm{mM}$ NADH was added. The $\mathrm{OD}_{(+\mathrm{S})}$ value was measured at a wavelength of $214 \mathrm{~nm}$. Saponin-lacking solution served as control [OD (- $^{-}$

s)]. The membrane blocking degrees at different glucose concentrations was calculated as follows:

$$
\text { Membrane blocking degree }(\%)=\frac{O D_{(+S)}-O D_{(-S)}}{O D_{(+S)}} \times 100 \%
$$

\section{b) Quantification of hydrogen peroxide}

The hydrogen peroxide concentrations under Endo@GOx-ER on- or off-state were measured using Amplex red. ${ }^{4}$ The assay was performed by mixing $25 \mu \mathrm{L}$ of supernatant and $50 \mu \mathrm{L}$ of the reaction mixture $\left(0.1 \mathrm{mM}\right.$ Amplex Red, HRP $\left.0.2 \mathrm{U} \mathrm{mL}^{-1}\right)$ and incubating for $30 \mathrm{~min}$ in the dark and at room temperature. The fluorescence intensity was measured using a Synergy HT multimode microplate reader (Biotek, Winooski, VA, USA).

\section{c) Determining malondialdehyde concentration}

A BCA protein concentration kit was used to determine protein concentration. The malondialdehyde (MDA) concentration was measured using an MDA kit (Nanjing Jiancheng Bioengineering Institute, China). ${ }^{5}$ The $\mathrm{OD}$ values of measuring tube $\left(\mathrm{OD}_{\mathrm{m}}\right)$, control tube $\left(\mathrm{OD}_{\mathrm{c}}\right)$, standard tube $\left(\mathrm{OD}_{\mathrm{s}}\right)$ and blank tube $\left(\mathrm{OD}_{\mathrm{b}}\right)$ were measured at $533 \mathrm{~nm}$.

The MDA concentration of Endo@GOx-ER at different glucose concentrations were calculated as follows: 


$$
\mathrm{MDA}(\mathrm{nmol} / \mathrm{L})=\frac{\mathrm{ODm}-\mathrm{ODc}}{\mathrm{ODs}-\mathrm{ODb}} \times \frac{\text { standard substance concentration }}{\text { protein concentration }}
$$

d) Assessment of membrane flow

0.1 mL of Endo@GOx-ER was immersed in glucose solutions of different concentrations (6 mL). $2 \mathrm{~mL}$ of the solution were mixed with $2 \mathrm{~mL}$ of DPH (1,6-Diphenyl-1,3,5-hexatriene) and incubated at $25^{\circ} \mathrm{C}$ for $30 \mathrm{~min}$. Then, the supernatant was got after a $3000 \mathrm{rpm}$ centrifugation for 10 min. The fluorescence polarization of each sample was measured at $25^{\circ} \mathrm{C}$ using a RF-5301PC fluorescence polarization system (Shimadzu, Kyoto, Japan). ${ }^{6}$ The excitation and emission wavelengths were $362 \mathrm{~nm}$ and $432 \mathrm{~nm}$, respectively. The excitation and emission slits were both $10 \mathrm{~nm}$. Polarized light in parallel $\left(\mathrm{I}_{\mathrm{v}}\right)$ or perpendicular $\left(\mathrm{I}_{\mathrm{h}}\right)$ was measured. Fluorescence polarization was defined as $\mathrm{P}=\left(\mathrm{I}_{\mathrm{v}}-\mathrm{I}_{\mathrm{h}}\right) /\left(\mathrm{I}_{\mathrm{v}}+\mathrm{I}_{\mathrm{h}}\right)$, while membrane flow was calculated as Membrane flow $=(0.5-\mathrm{P}) / \mathrm{P}^{2}$.

\section{Cell migration analysis}

Cell migration was assessed by a wound scratch-healing assay. ${ }^{7}$ Briefly, $4 \mathrm{~T} 1$ cells were seeded in 6-well plates. The adherent cells were scraped using a pipette tip, and cells were washed with PBS to remove debris. After fully bonding, add free Endo $(5.0 \mathrm{mg} / \mathrm{mL}, 200 \mu \mathrm{L})$ and Endo@GOx-ER $(200 \mu \mathrm{L})$ and then cultured in high glucose DMEM. Cell migration was monitored after 6 and 24 hours of incubation by microscopy. Cell migration was quantified by measuring the distance of the migrated cells from the initial scratch.

\section{Tumour xenograft models and treatment regimens}

The in vivo antitumor efficacy and safety were evaluated using $4 \mathrm{~T} 1$ tumor-bearing mice. ${ }^{8}$ Briefly, $1 \times 10^{6} 4 \mathrm{~T} 1$ breast cancer cells were subcutaneously injected into the right axilla of the 
female BALB/c mice. When the tumors reached an average volume of $100 \mathrm{~mm}^{3}$, the mice were randomly allocated into five groups (10 mice per group), and intravenously injected with saline (as control) and an equal dose of PBS+RT (twelve injections of 0.1 PBS were given daily followed by X-ray with 4 Gy every 3 days for 9 days). Free Endo+RT $(2.5 \mathrm{mg} / \mathrm{kg}$ body weight by daily injections for 12 days, and irradiated with 4 Gy every 3 days for 9 days). Endo@GOx-ER+RT (administered every 3 days at the dose of $2.5 \mathrm{mg} / \mathrm{kg}$ body weight for 12 days, and irradiated with X-ray at the dose of 4 Gy every 3 days for 9 days). Body weight and tumor volume $\left(V=a b^{2} / 2\right.$, where $a$ was the major axis, and $b$ was the minor axis, as measured by slide caliper) were recorded every three days after the initiation of the treatment. Mice were observed daily for survival. At the end of the experiment, mice were sacrificed, and the tumors were excised, weighed and photographed.

\section{In vivo release behavior of Endo@GOx-ER}

The release behavior of Endo@GOx-ER in vivo would cause the changes of Endo plasma concentration. So, after the injection of free Endo or Endo@GOx-ER, the blood was collected at predetermined time and the Endo concentration was determined by HPLC.

To compare Endo concentration in tumor bulk between free Endo group and Endo@GOx-ER group, the mice were sacrificed $10 \mathrm{~h}$ after the treatment of free Endo or Endo@GOx-ER, and the tumors were collected to extract and determine the Endo concentration by HPLC.

\section{Detection of jugular venous oxygen saturation ( $\left.\mathrm{SjO}_{2}\right)$}

To study the influence of catalysis reaction during the release of Endo on the blood oxygen. After the treatment of PBS or Endo@GOx-ER, the mice were feed with food for $0.5 \mathrm{~h}$ to raise the 
BGL. The blood was collected at predetermined time and the jugular venous oxygen saturation $\left(\mathrm{SjO}_{2}\right)$ was determined by blood gas analyzer (GEM Premier 3000, USA).

\section{Detection and observation of hematological indicators}

After the mice were treated with Endo@GOx-ER or PBS, the glucose levels were tested by automated biochemical analyzer (Trilogy, France) at predetermined time. Whole blood $\mathrm{pH}$ has been determined in vitro by using near-infrared spectroscopy over the wavelength range of 1500 to $1785 \mathrm{~nm},{ }^{9}$ and the $\mathrm{H}_{2} \mathrm{O}_{2}$ concentration was determined by the colorimetric method. ${ }^{10}$

Mice were sacrificed on days 0, 3, 6, 9, and 12 after intravenous injection of Endo@GOxER. Colorimetric assessment of the $\mathrm{H}_{2} \mathrm{O}_{2}$ concentration was conducted at the indicated time-points. Additionally, hematocrit (HCT), hemoglobin (HGB), mean red blood cell volume (MCV), mean red blood cell hemoglobin $(\mathrm{MCH})$, and mean red blood cell hemoglobin concentration (MCHC) were measured.

\section{Micro-PET}

The tracer ${ }^{18} \mathrm{~F}-\mathrm{FDG}$ was produced in-house using the Siemens RDS-11 cyclotron, and the ${ }^{18} \mathrm{~F}$-MISO PET study was performed using a CTI/Siemens EXACT/HR whole-body PET scanner. ${ }^{11}$ Tumor-bearing mice were intravenously injected with $100 \mu \mathrm{L}$ of a saline suspension containing ${ }^{18} \mathrm{~F}$-MISO $(75 \mu \mathrm{Ci} /$ mouse $)$ to evaluate the hypoxic status after the indicated treatments. The imaging was conducted on an Inveon PET/CT system (Siemens, Malvern, PA), one hour after the intravenous injection of ${ }^{18} \mathrm{~F}-\mathrm{MISO}$. During the scanning phase (but not during ingestion), sedatives were used when necessary.

\section{PA Imaging}


To evaluate the PA performance of Endo@GOx-ER, 4T1 tumor-bearing mice were randomly allocated into two groups $(n=3)$, and intravenously injected with free Endo and Endo@GOxER. ${ }^{12}$ The PA images were collected at pre, 3 , and 6 days and the average PA-signal intensity value of the tumor regions was measured. The imaging was conducted on A Vevo LAZR Photoacoustic Imaging System (Visual Sonics Inc., Toronto, Canada).

\section{Immunofluorescence}

After tumor tissues were fixed in 4\% paraformaldehyde for 24 hours, they were paraffinembedded, sliced, dewaxed in xylene, and then rehydrated by graded alcohol. Antigen retrieval was performed in citrate buffer $(\mathrm{pH}$ 6.0). The sections were blocked in $2 \%$ normal goat serum for 1 hour and then stained with primary antibodies as follows: anti-CD31 antibody (1:500), anti-HIF$1 \alpha$ antibody (1:50) and $\alpha$-SMA antibody (1:100). Sections were washed and incubated with goat anti-rabbit IgG-FITC (1:200) for 40 minutes at room temperature. Peripheral cell coverage levels were expressed as the percentage of cells surrounding the CD31 blood vessels. The proportion of hypoxia in the tumor sections was expressed as the area of HIF-1 $\alpha$ staining and pimonidazole staining.

\section{Statistical analysis}

All values were averaged and expressed as the mean \pm standard deviation. Statistical analysis was performed using the SPSS 24.0 statistical analysis software package. The differences between groups were evaluated using the Student's $t$-test when comparing only two groups or using oneway ANOVA with post hoc tests when more than two groups were compared. Differences were considered statistically significant at $P<0.05$. 


\section{SUPPLIMENTARY RESULTS}
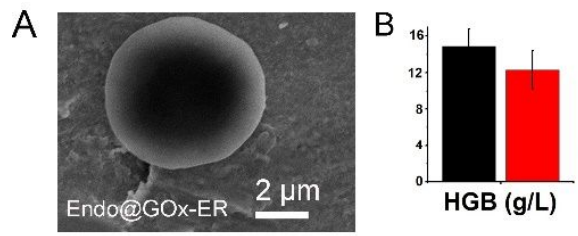
HGB (g/L)
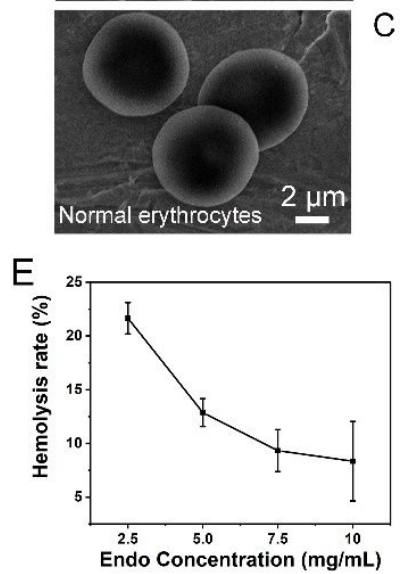

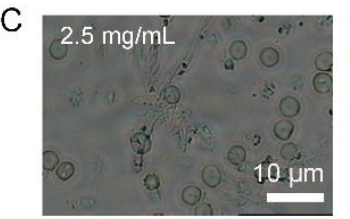

F

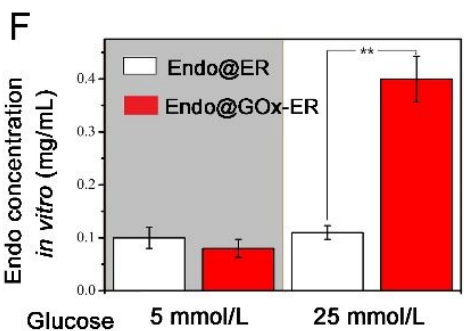

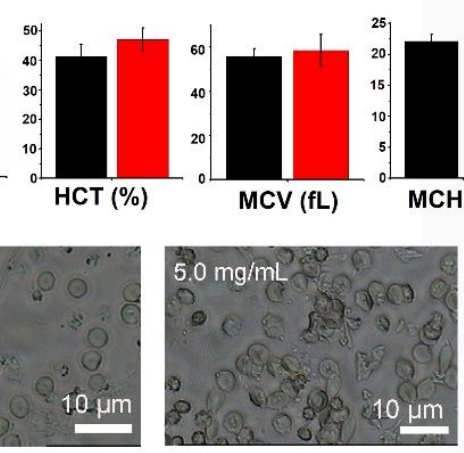

G
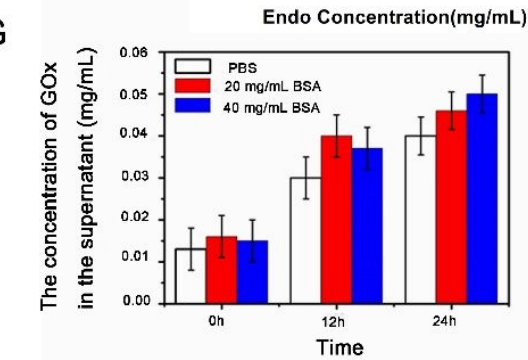

Figure S1. Characterization of Endo@GOx-ER. (A) Enlarged scanning electron microscopic image of the Endo@GOx-ER and normal erythrocytes. Endo-loaded erythrocytes maintained their physiological shape and size as compared with normal erythrocytes (B) Hematological parameters of native erythrocyte and Endo@GOx-ER, including hemoglobin (HGB), hematocrit (HCT), mean corpuscular volume $(\mathrm{MCV})$, mean corpuscular hemoglobin $(\mathrm{MCH})$, and mean corpuscular hemoglobin concentration (MCHC). There were no statistically significant differences between Endo@GOx-ER and native erythrocyte in the hematological parameters tested. (C) Pictures of ER in different Endo concentration solution. Most of ER swelled in the $2.5 \mathrm{mg} / \mathrm{mL}$ Endo solution and kept original structure in the $5.0 \mathrm{mg} / \mathrm{mL}$ Endo solution. (D) Relationship between initial Endo concentration and cell recovery. A positive correlation between the recovery ratio and initial Endo concentration was observed. (E) Relationship between initial Endo concentration and hemolysis rate. (F) The glucose-responsive effect of Endo@ER and Endo@GOx-ER in 5 mM or 25 mM of 
D-glucose. GOx was expected to act as a "glucose-regulated switch" to control the release of Endo. Under hyperglycemia (glucose concentration $25 \mathrm{mM}$ ), small amount of Endo was released in the Endo@ER group. On the contrary, large amount Endo release was witnessed and the release amount was enhanced as the concentration of GOx increased. ${ }^{* *} P<0.01$. (G) The anchoring test of biotin-GOx in the presence of BSA. 2 mL of Endo@GOx-ER $\left(0.5 \mathrm{mg} 10^{10}\right.$ cells GOx), was kept in PBS with $20 \mathrm{mg} / \mathrm{mL}$ and $40 \mathrm{mg} / \mathrm{mL}$ bovine serum albumin (BSA). The concentration of GOx in the supernatant did not significantly increase in the presence of BSA $(P>0.05)$, which might partly illustrate that biotin-GOx could anchor on the surface of erythrocyte stably even in the presence of large amount of competitive proteins. 

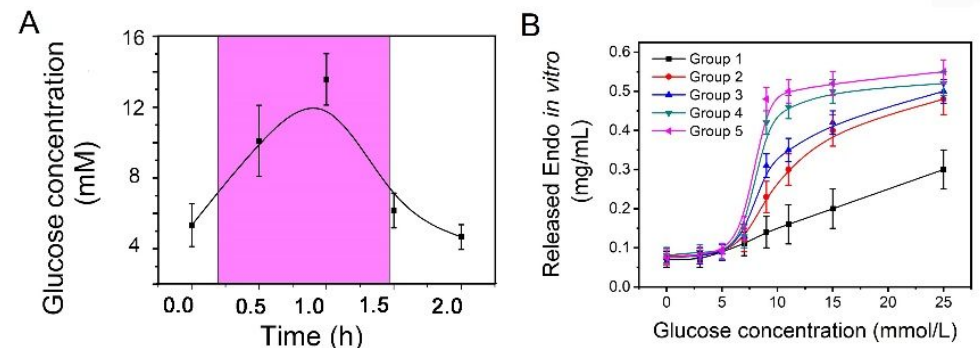

Group 1, Initial GOx $0.1 \mathrm{mg} / 10^{6}$ cells Group 2, Initial GOx $0.5 \mathrm{mg} / 10^{6}$ cells Group 3, Initial GOx $1 \mathrm{mg} / 10^{6}$ cells Group 4, Initial GOx $2 \mathrm{mg} / 10^{6}$ cells Group 5, Initial GOx $4 \mathrm{mg} / 10^{6}$ cells
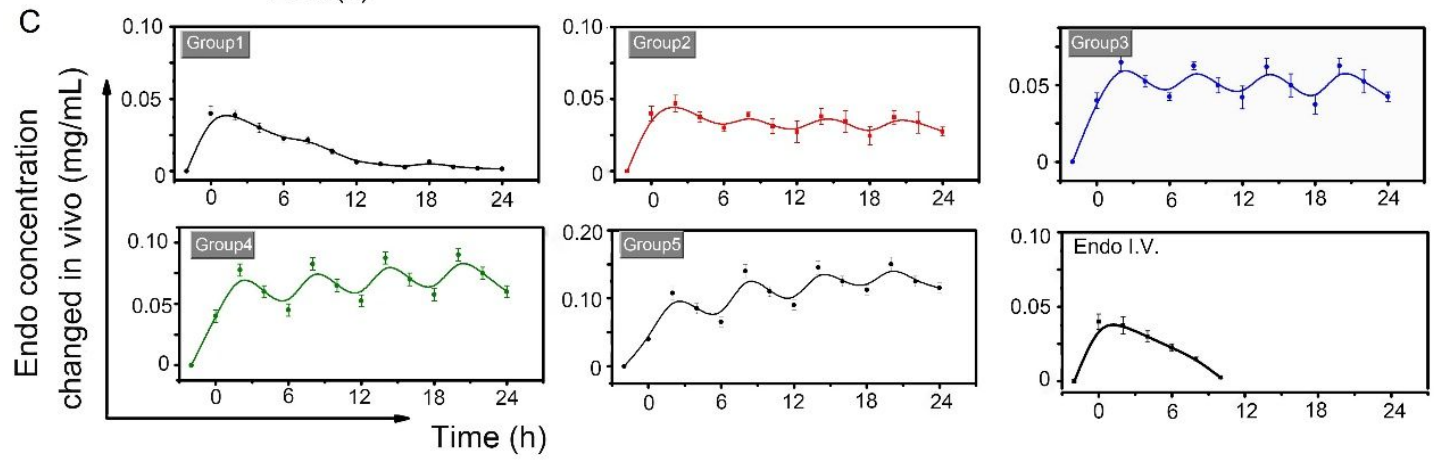

Figure S2. (A) Changes in blood glucose concentration after a meal. Blood sugar reached a peak at $0.5-1.5 \mathrm{~h}$ after a meal and decreased back to the physiological levels after $2 \mathrm{~h}$. There is approximately a sustained for 1.2-1.5h Endo release after a meal when the concentration of glucose is over $7 \mathrm{mM}$ (pink area). (B) In vitro Endo release rate in different glucose concentrations. Group 1: Initial GOx $0.1 \mathrm{mg} / 10^{6}$, Group 2: Initial GOx $0.5 \mathrm{mg} / 10^{6}$, Group 3: Initial GOx $1 \mathrm{mg} / 10^{6}$, Group 4: Initial GOx $2 \mathrm{mg} / 10^{6}$, Group 5: Initial GOx $4 \mathrm{mg} / 10^{6}$. Interestingly, the released rate of Endo from Endo@GOx-ER was profoundly higher in glucose levels over 7 mM. (C) The Endo concentration changed in vivo after administration of Endo@GOx-ER or free Endo. Endo injected intravenously can be cleared from the organisms by 10 hours of administration; therefore, repeated administration is necessary to ensure sustained anti-angiogenic effects. Endo released from Endo@GOx-ER in vivo depended on the concentration amount of GOx on the Endo@GOx-ER surface. The Endo levels in the blood fluctuated, as the Endo would release from Endo@GOx-ER because the amount of Endo released at hyperglycemia would make up the blood clearance. The 
amount of Endo released associated with the amount of GOx. Higher levels of GOx on Endo@GOx-ER resulted in a faster release of Endo. The Endo concentration in Group 2 (initial GOx $0.5 \mathrm{mg} / 10^{10}$ ) and Group 3 (initial GOx $1 \mathrm{mg} / 10^{10}$ ) had only small fluctuations. A rapid Endo release would greatly impact the effective duration time of the agents. 


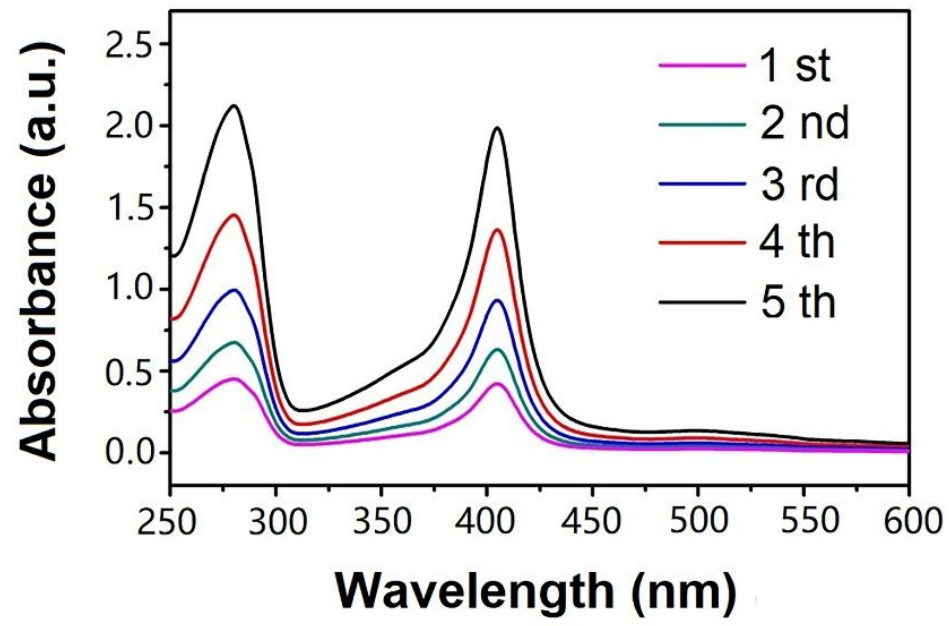

Figure S3. UV absorption spectra of Endo released from Endo@GOx-ER at various times after incubation under hyperglycemic conditions $(25 \mathrm{mM})$. It showed an increment in the absorbance positioned at $405 \mathrm{~nm}$ (Endo). 

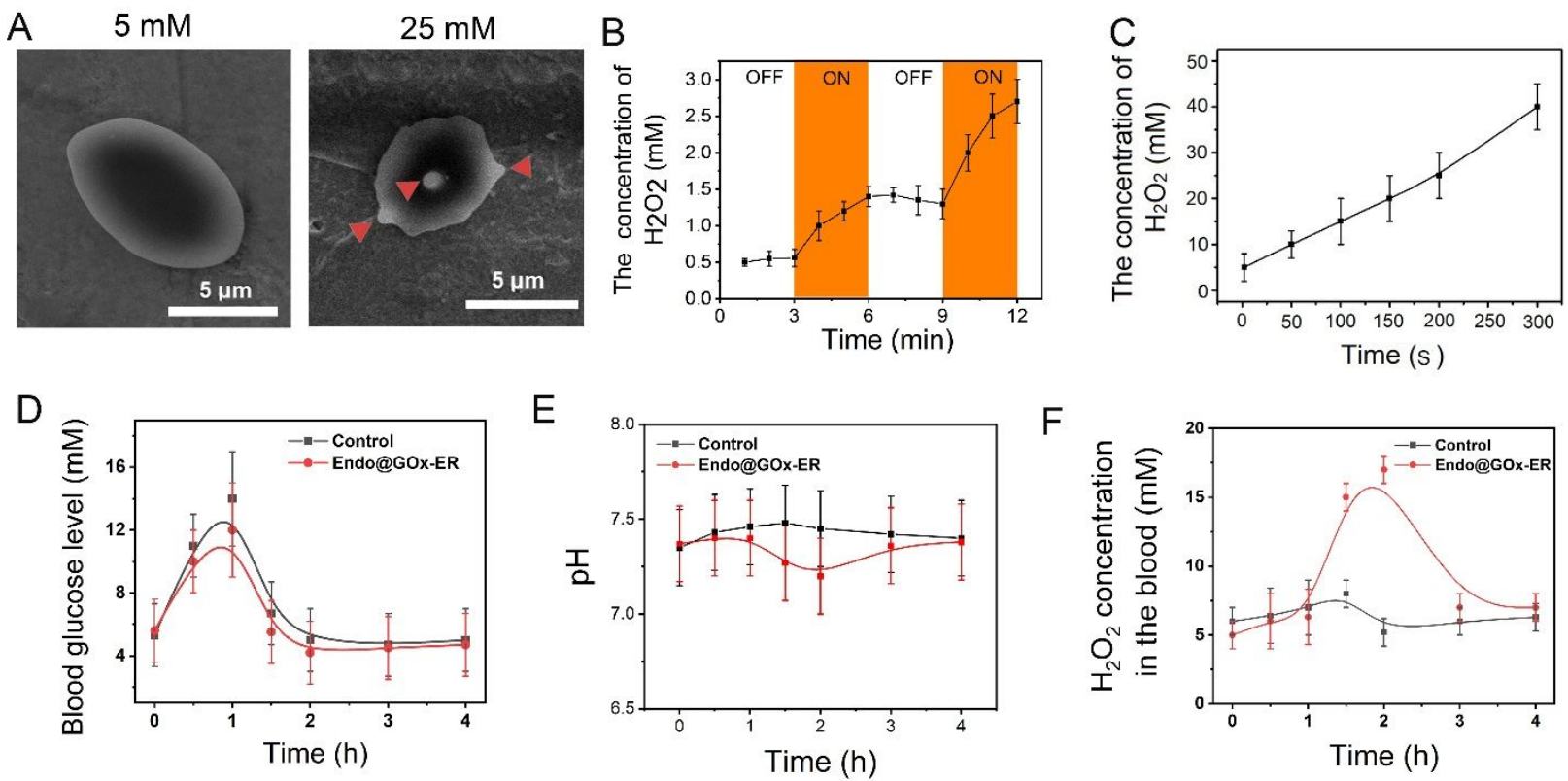

Figure S4. (A) SEM image of Endo@GOx-ER as it was immersed in normoglycemic solution (glucose concentration $5 \mathrm{mM}$ ) and hyperglycemic solution (glucose concentration $25 \mathrm{mM}$ ). The high local concentration of $\mathrm{H}_{2} \mathrm{O}_{2}$ would form pores (the red triangle) on the lipid membranes of erythrocyte, giving rise to the release of inner cargo. (B) The change of $\mathrm{H}_{2} \mathrm{O}_{2}$ concentration during the closed-loop release of Endo@GOx-ER. (C) The generation rate of $\mathrm{H}_{2} \mathrm{O}_{2}$ by GOx. The generation rate of $\mathrm{H}_{2} \mathrm{O}_{2}$ by GOx $(1.0 \mathrm{mg})$ was as high as $8 \mathrm{mmol} / \mathrm{L} / \mathrm{min}$ in $25 \mathrm{mmol} / \mathrm{L}$ glucose PBS solution at $37{ }^{\circ} \mathrm{C} \quad\left(\mathrm{pH}\right.$ 7.4). Change of blood glucose level (D), blood $\mathrm{pH}(\mathrm{E})$ and $\mathrm{H}_{2} \mathrm{O}_{2}$ concentration (F) in the blood after the administration of Endo@GOx-ER in vivo. With regard to the $\mathrm{BGL}, \mathrm{pH}$ value and produced $\mathrm{H}_{2} \mathrm{O}_{2}$, they could be slowly adjusted to the normal level by the body microenvironment as previous reported work and would not cause systemic toxicity. 

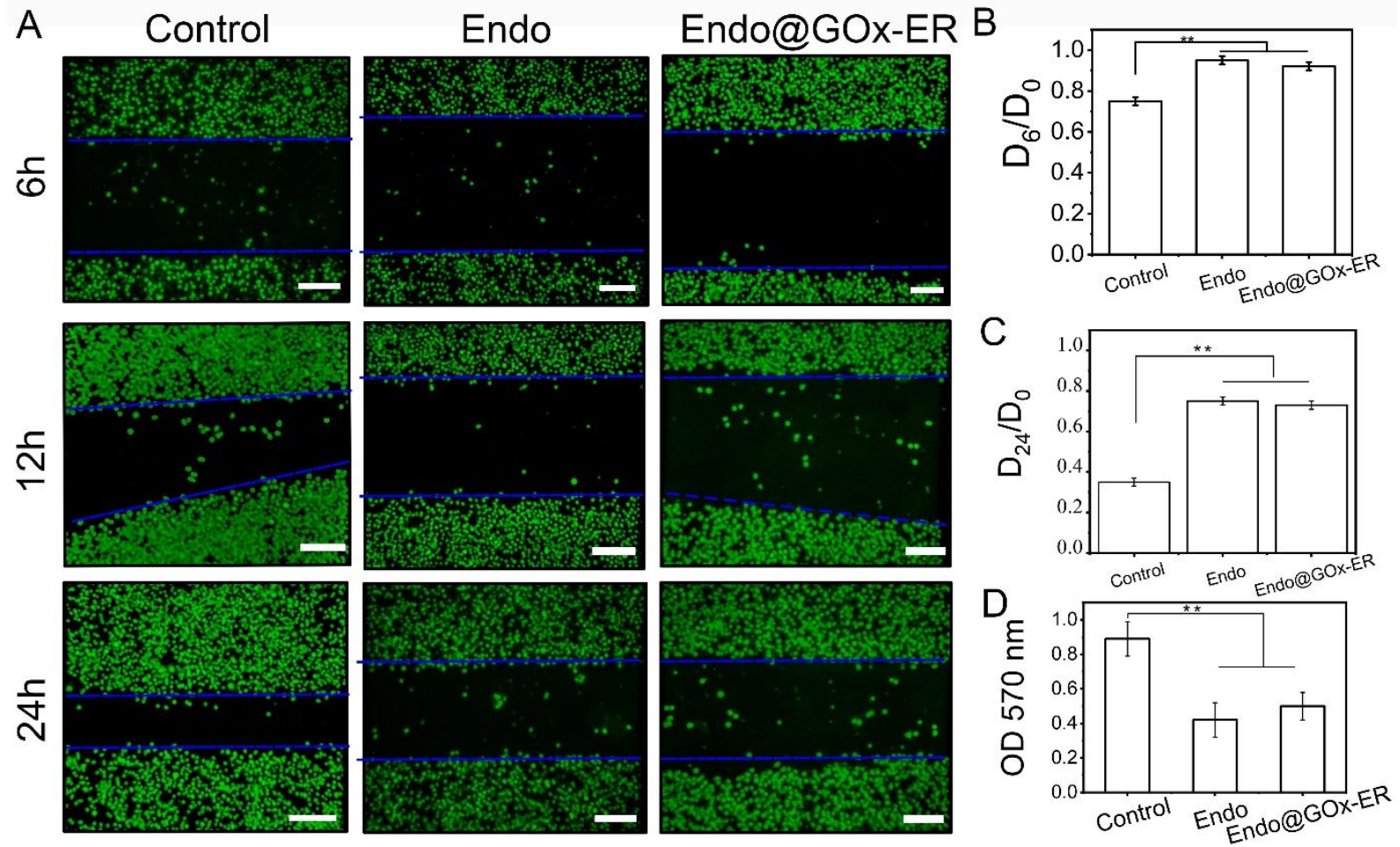

Figure S5. Endo@GOx-ER decreases the cell migration capacity of 4T1 cells. (A) Representative images of the wound healing assay for Endo $(500 \mathrm{ng} / \mathrm{mL}, 200 \mu \mathrm{L})$, and Endo@GOx-ER (14.2 $\mathrm{ng} / \mathrm{mL}, 7 \mu \mathrm{L})$ treatment compared to that of untreated group in $4 \mathrm{~T} 1$ cells. Bar $=100 \mu \mathrm{m} .(\mathrm{B}, \mathrm{C})$ represent the wound healing rate prior to $(0 \mathrm{~h})$ after treatment of $6 \mathrm{~h}$ and $24 \mathrm{~h}$. DMSO $(0.5 \% \mathrm{v} / \mathrm{v})$ was used as a negative control (means \pm SD). (D) The effects of Endo@GOx-ER administration on the invasion capacity of $4 \mathrm{~T} 1$ tumor cells. ${ }^{*} * P<0.01$. There was no significant difference in the cell migration capacity of 4T1 cells between free Endo and Endo@GOx-ER treated groups, demonstrating that the $\mathrm{H}_{2} \mathrm{O}_{2}$ generated by the GOx would not denature the loaded Endo. 

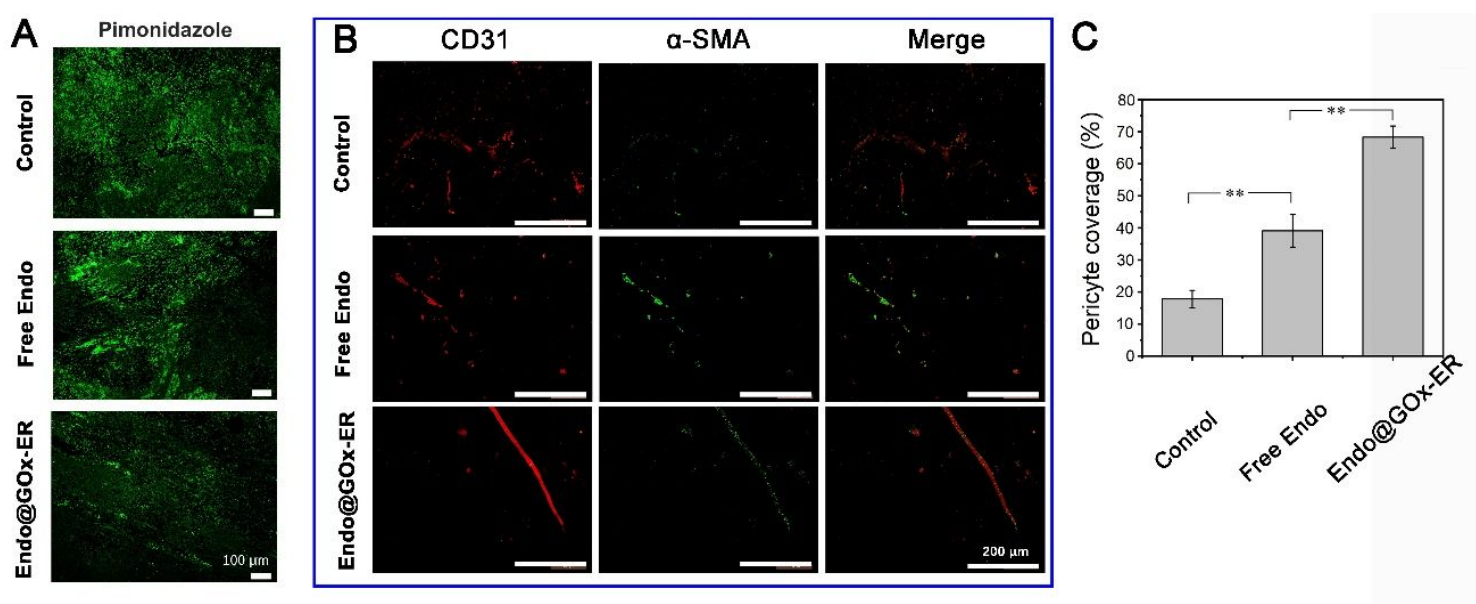

Figure S6. (A) Representative immunofluorescence microscopy images of tumor sections after staining for pimonidazole staining. Scale bars $=100 \mu \mathrm{m}$. These results indicate that treatment with Endo@GOx-ER combined with RT resulted in decreased hypoxia. (B) Double staining for CD31 and $\alpha$-SMA demonstrated that Endo@GOx-ER treatment increased the proportion of pericytecovered vessels. The results indicated that Endo@GOx-ER increased the integrity of the endothelium by increasing pericyte coverage, indicating that the tumor vessels were more mature. Scale bars $=200 \mu \mathrm{m}$. (C) The pericyte coverage in tumors treated with Endo@GOx-ER were maintained at high levels, ${ }^{* *} P<0.01$. 

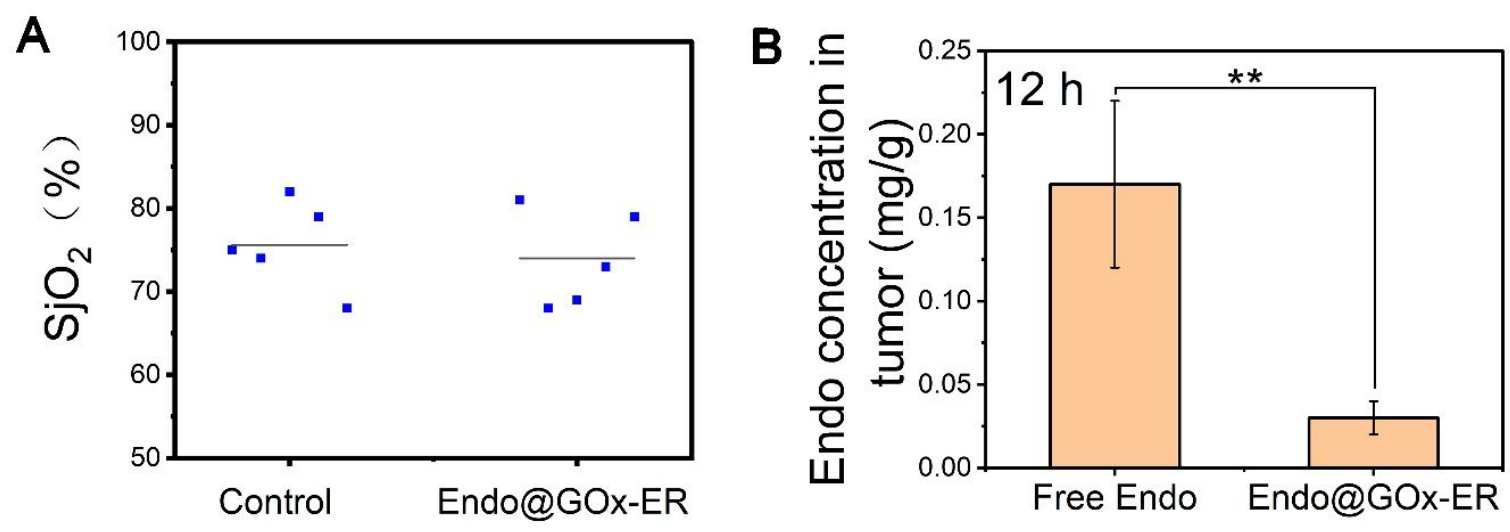

Figure S7. (A) The change of jugular venous oxygen saturation $\left(\mathrm{SjO}_{2}\right)$ after treat with $0.1 \mathrm{~mL}$ PBS (set as control) or 0.1mL Endo@GOx-ER, n=5. From the result, there was no difference observed in $\mathrm{SjO}_{2}$ between the two groups. We can draw a conclusion that the release behavior of Endo@GOx-ER would not decrease the blood oxygen concentration. (B) The Endo released rate of Endo@GOx-ER under normoxia and hypoxia condition, **P<0.01. The Endo@GOx-ER released few Endo under hypoxia condition. 


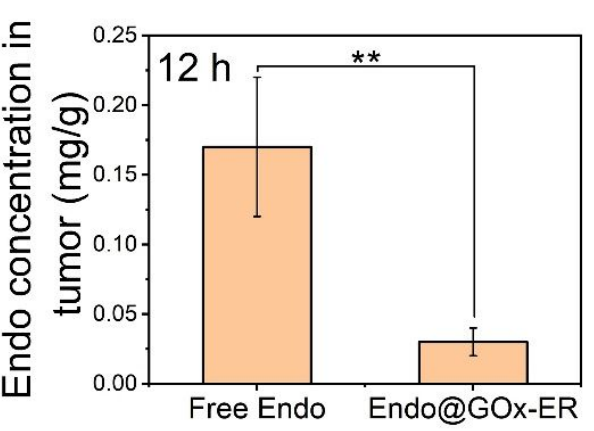

B
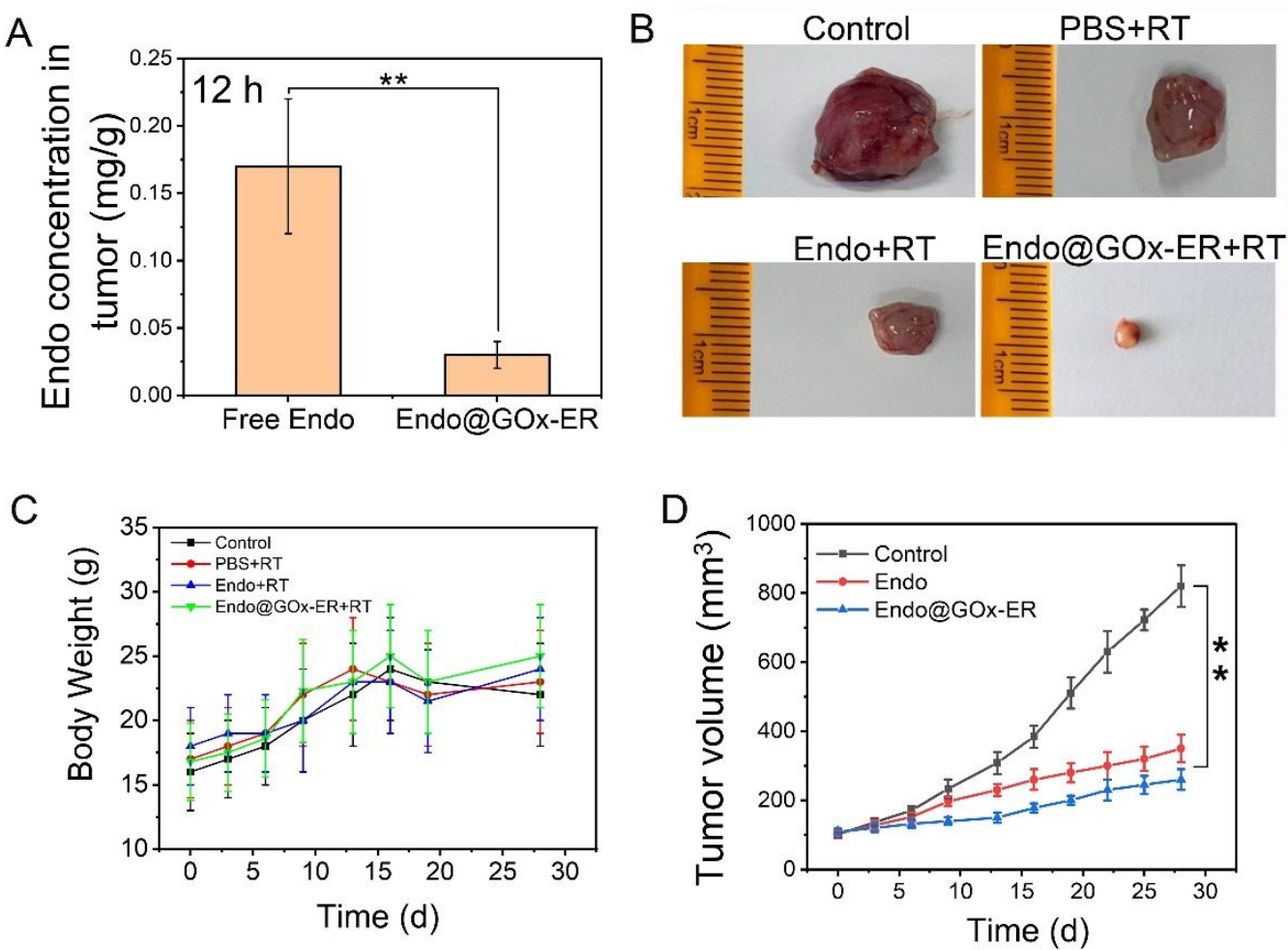

Figure S8. (A) Endo concentration was detected in the tumor bulk $12 \mathrm{~h}$ after the injection of free Endo or Endo@GOx-ER. (B) Representative images taken at the end of the study. The tumor-bearing mice were randomly allocated into four groups, and intravenously injected with different formulations as follows: (1) PBS group, administrated with PBS (0.1 mL, once a day) for 12 days. (2) PBS + RT group, administrated with PBS $(0.1 \mathrm{~mL}$, once a day) for 12 days and irradiated with X-ray (4 Gy, once every 3 days) for 9days; (3) Free Endo + RT group, administrated with Free Endocontained PBS solution $(2.5 \mathrm{mg} / \mathrm{Kg}$ body weight, once a day) for 12 days and irradiated with Xray (4 Gy, once every 3 days) for 9 days; (4) Endo@GOx-ER + RT group, administrated with Endo@GOx-ER-contained PBS solution ( $2.5 \mathrm{mg} / \mathrm{kg}$ body weight, once every 3 days) for 12 days and irradiated with X-ray (4 Gy, once every 3 days) for 9 days. (C) Mice body weight changes over time. $n=10$. (D) Relative tumor growth curves of mice after intravenous injection of different 
treatments for 28 days. $* * P<0.01$.
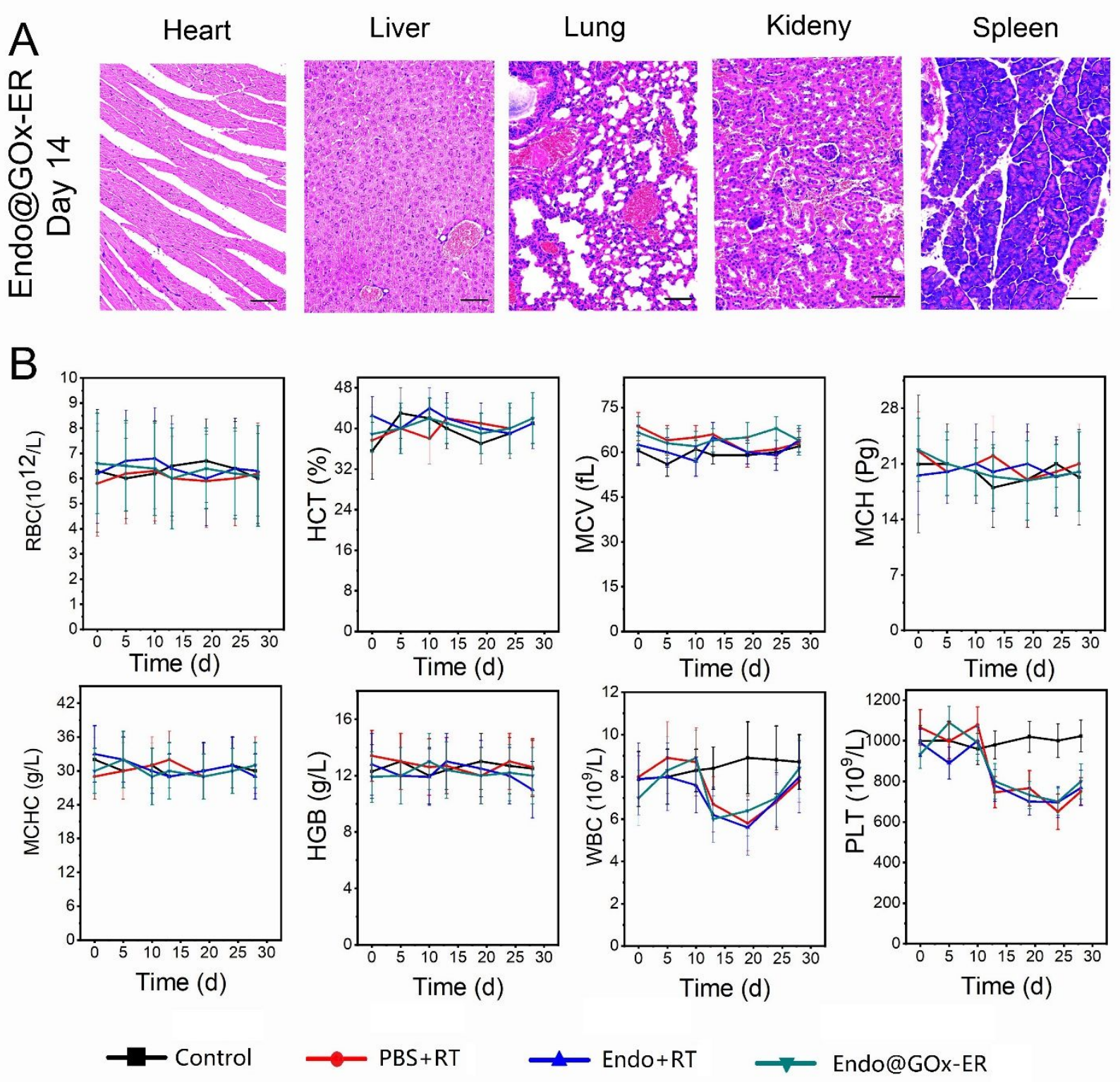

Figure S9. Assessment of the potential long-term toxicity caused by Endo@GOx-ER (A)

Pathological analysis using H\&E staining was conducted on the tissue samples collected at days 14 post i.v. injection of Endo@GOx-ER at dosage equivalent to that employed for the antitumoral 
study. Scale bars: $50 \mu \mathrm{m}$. (B) Hematological parameters. Red blood cells (RBC), hematocrit (HCT), mean corpuscular volume $(\mathrm{MCV})$, mean corpuscular hemoglobin $(\mathrm{MCH})$, mean corpuscular hemoglobin concentration (MCHC), hemoglobin (HGB), white blood cells (WBC), and platelet count $($ PLT) were measured. Bar $=200 \mu \mathrm{m}$. 


\section{REFERENCES}

(1) Arias, M.; Quijano, J.C.; Haridas, V.; Gutterman, J.U.; Lemeshko, V.V. Red blood cell permeabilization by hypotonic treatments, saponin, and anticancer avicins, Biochim. Biophys. Acta 2010, 1798, 1189-1196.

(2) Xia, D.; He, H.; Wang, Y.; Wang, K.; Zuo, H.; Gu, H.; Xu, P.; Hu, Y. Ultrafast glucoseresponsive, high loading capacity erythrocyte to self-regulate the release of insulin. Acta Biomater. 2018, 69, 301-312.

(3) Yuan, H.L.; Liu, X.L.; Liu, Y.J. Solanum Nigrum polysaccharide (SNL) extract effects in transplanted tumor-bearing mice--erythrocyte membrane fluidity and blocking of functions, Asian Pac. J. Cancer Prev. 2014, 15, 10469-10473.

(4) Deng, Q.; Liu, Q.; Zhang, H.; Fan, W.; Li, J.; Kang, J.; He, H.; Huang, F. Melatonin enhances hydrogen peroxide-induced apoptosis in human dental pulp cells, J. Res. Dent. Sci. 2019, 14, 370377.

(5) Maryam, K.; Khalil, Ansarin.; Abolghasem, J. Reliability of malondialdehyde as a biomarker of oxidative stress in psychological disorders, Bioimpacts 2015, 5, 123-127.

(6) Herring, J.; Smith, S. A.; Mcmichael, M.; Obrien, M.; Ngwenyama, T. R.; Corsi, R.; Galligan, A.; Beloshapka, A. N.; Deng, P.; Swanson, K. S. Microparticles in stored canine RBC concentrates. Vet. Clin. Pathol. 2013, 42, 163-169.

(7) César, R. Gentian Violet Used as an Epithelial Cell Monolayer Stain in the Scratch Wound Healing Assay. Anal quant cytopathol histpathol, 2016, 38, 137-138.

(8) Zhang, R.; Zhu, Z.; Lv, H.; Li, F.; Sun, S.; Li, J.; Lee, C. Immune Checkpoint Blockade Mediated by a Small-Molecule Nanoinhibitor Targeting the PD-1/PD-L1 Pathway Synergizes with Photodynamic Therapy to Elicit Antitumor Immunity and Antimetastatic Effects on Breast Cancer, Small, 2019, 15: e1903881.

(9) Rustum, A.M. Measurement of ibuprofen in human whole blood by reversed-phase ion-paired high-performance liquid chromatography using a $\mathrm{pH}$-stable polymeric column, J. Chromatogr. B: 
Biomed. Sci. Appl. 1990, 526: 246-253.

(10) Chen, H.; Tian, J.; He, W.; Guo, Z. $\mathrm{H}_{2} \mathrm{O}_{2}$-activatable and $\mathrm{O}_{2}$-evolving nanoparticles for highly efficient and selective photodynamic therapy against hypoxic tumor cells, J. Am. Chem. Soc. 2015, 137, 1539-1547.

(11) Xia, D.; Xu, P.; Luo, X.; Zhu, J.; Gu, H.; Huo, D.; Hu, Y. Overcoming Hypoxia by Multista ge Nanoparticle Delivery System to Inhibit Mitochondrial Respiration for Photodynamic Therap y, Adv. Funct. Mater. 2019, 29. 201807294.

(12) Daoudi, K.; Hoogenboom, M.; den Brok, M.; Eikelenboom, D.; Adema, G. J.; Futterer, J. J.; de Korte, C. L. In vivo photoacoustics and high frequency ultrasound imaging of mechanical hig $\mathrm{h}$ intensity focused ultrasound (HIFU) ablation, Biomed. Opt. Express 2017, 8, 2235-2244. 